\title{
PRÁTICAS E PERCEPÇÕES \\ QUANTO AO GERENCIAMENTO DE \\ RESÍDUOS SÓLIDOS INDUSTRIAIS \\ NO ESTADO DE SANTA CATARINA
}

Abel Corrêa de Souza ${ }^{1}$

Fernanda Moro Broleze ${ }^{2}$

Resumo: Buscando identificar o comportamento ambiental voltado ao gerenciamento de resíduos industriais em Santa Catarina, este estudo procedeu através de uma pesquisa de campo com abordagem qualitativa, utilizando um questionário com dez questões abertas, destinadas aos mais variados setores. Em predominância, as indústrias apresentam práticas voltadas a correta destinação e tem percepções positivas relacionadas aos custos dispendidos. Tais procedimentos descrevem que o comportamento ambiental não possui um padrão por segmento e favorece o estudo dos resíduos voltados as suas características e classificações em detrimento de uma abordagem em uma organização com geração de um resíduo específico.

Palavras-chave: Responsabilidade Social; Sustentabilidade; Resíduos Sólidos.

1 Universidade do Extremo Sul Catarinense - UNESC. E-mail: acs@unesc.net

2 Universidade do Extremo Sul Catarinense - UNESC. E-mail: fernandabroleze@gmail.com

Revbea, São Paulo, V. 14, № 4: 386-404, 2019. 


\section{Introdução}

A caracterização dos resíduos gerados pelas indústrias Catarinenses apresenta-se bastante diversificada, apontando maioritariamente para os resíduos de produção, apesar do grande volume de empresas que monitoram a geração de resíduos por meio de alguma ferramenta, este fato pode indicar a falta de otimização e desperdício de matérias primas no processo produtivo.

A revolução industrial acentuou significativamente a geração de resíduos sólidos. Marques (2005), diz que as indústrias passaram a utilizar maiores quantidades de recursos naturais para atenderem as demandas de um mercado cada vez mais consumista.

De acordo com Layrargues (2003), o cenário brasileiro, desde 1975, sofre um processo gradual de incorporação da relação ambiental nas empresas, que abrange três fases. A fase da integração compulsória, de 1975 a 1992, quando predominou a tendência das normas ambientais compulsórias estabelecidas unicamente pelo Estado para adequação das empresas. A fase transitória, de 1992 a 1997, quando ocorreu o processo de diálogo e negociação entre empresariado e órgãos governamentais em busca de estratégias mais realistas para a iniciativa privada adequar-se as normas ambientais. E a fase de integração voluntária, de 1997 em diante, quando predomina a tendência das normas ambientais voluntárias para a empresa assumir a pauta ambiental.

Segundo Ribeiro (2010), os gastos relacionados a área ambiental podem ser elevados, porém quando bem administrados podem resultar em redução e economia de custos, principalmente relacionados a otimização de matéria prima, produtividade e competitividade no mercado, além de evitar gastos com recuperação de áreas degradadas e multas por danos ambientais.

As atividades empresariais possuem diversos reflexos no ambiente natural e as despesas ambientais possuem fator de grande relevância na formação do custo dos produtos, portanto este estudo busca identificar as ações desenvolvidas pelas indústrias Catarinenses relacionadas ao gerenciamento dos resíduos sólidos industriais.

\section{Fundamentação teórica}

\section{Responsabilidade social empresarial}

De acordo com o instituto Ethos (2004), a responsabilidade social passou a ser valorizada no Brasil a partir da década de 1990. Sua relevância no país acontece devido à grande quantidade de carências e desigualdades, espera-se que as empresas auxiliem na construção de uma sociedade melhor.

Para Oliveira (1984), a responsabilidade social pode ser interpretada como uma obrigação legal, o comportamento responsável, ou atos de filantropia que devem ser de responsabilidade da empresa. Sertek (2006), nota uma sensibilização maior relacionada aos problemas gerados pela atividade

revista brasileira educação ambiental 
das empresas, destacando o nível de informação a respeito de qualidade de produtos e impactos que eles geram ao meio ambiente. Tais questões relacionadas a responsabilidade social começam a pesar na decisão de compra.

\section{Sustentabilidade e Desenvolvimento Sustentável}

Para Lélé (1991), o conceito de sustentabilidade, é originado a partir do contexto de recursos renováveis, e adotado pelo movimento ambientalista. De acordo com Ayres (2008), e Boff (2017), a sustentabilidade funciona como uma norma sobre a forma que os seres humanos devem agir em relação a natureza, e as suas responsabilidades perante as futuras gerações.

De acordo com Bartelmus (2003), a sustentabilidade em âmbito empresarial é definida como a desmaterialização da atividade econômica, uma vez que a diminuição do processamento de materiais resulta em uma menor pressão sobre os sistemas naturais e amplia os serviços ambientais para a economia. Para Sachs (2004), o desenvolvimento sustentável vem se moldando em debates internacionais e aponta discussões para reparar desigualdades e melhorar a condição de vida das pessoas, articulando objetivos econômicos, sociais e ambientais de forma equilibrada à sociedade.

Segundo Romeiro (2012), desde que surgiu, nos anos 1970, com o nome de ecodesenvolvimento, sua definição vem sendo alvo de controvérsias. Suas dificuldades não aparecem apenas na sua prática em sociedade, mas também em seu conceito teórico. O mais tradicional é o descrito pela ONU em 1987, elaborado pela World Commission on Environment and Development WCED: "satisfazer as necessidades do presente sem comprometer a capacidade de as futuras gerações satisfazerem suas próprias necessidades".

Barbosa (2007), descreve três componentes fundamentais para o desenvolvimento sustentável, são eles: crescimento econômico, proteção ao meio ambiente, e igualdade social. Estes, associados a mudança de padrões empresariais, passaram por uma idealização de desenvolvimento sustentável, originando o Triple Bottom Line da sustentabilidade.

\section{Educação Ambiental}

Em nível mundial a questão ambiental ganhou notória repercussão com a Conferência das Nações Unidas sobre o Meio Ambiente, realizada em Estocolmo em 1972, nesta conferência a questão da educação para o meio ambiente também foi discutida. Segundo Lima (1984), trata de uma abordagem multidisciplinar, abrangendo todos os níveis de ensino com objetivo de sensibilizar a população para os cuidados ambientais.

Keim (1984), destaca que a educação para o ambiente deve reformular constantemente seus métodos, conteúdos e orientações de acordo com as 
novas situações que surgirem. Esta educação deverá ser responsável pelas decisões que incidem sobre o meio ambiente.

Para Roos e Becker (2012) a Educação Ambiental funcionaria como um componente essencial no processo de formação e educação permanente, sua abordagem direcionada a solução de problemas contribuiria para um maior envolvimento do público e tornaria o sistema educativo mais relevante e realista.

\section{Resíduos Industriais e Resíduos Sólidos}

De acordo com Santaella (2014), o conceito de resíduos sólidos sofreu variação ao longo do tempo, devido aos avanços tecnológicos, a conscientização com o meio ambiente, e a necessidade financeira de reaproveitamento de materiais que não possuem mais utilidade em determinados fins, mas podem servir de matéria prima para outros.

Para o Sebrae (2012), tudo aquilo que no passado aprendemos a chamar de lixo deve ser chamado atualmente de resíduo sólido. Demajorovic (1995), diz que o lixo não possui qualquer tipo de valor e deve ser descartado, já os resíduos possuem valor econômico agregado pois possibilitam ou estimulam o reaproveitamento ainda no processo produtivo, ou geram a criação de empresas que o utilizam como insumo produtivo

Cinquetti (2004), aponta que a questão dos resíduos remonta a produção dos bens, ele é o principal responsável pelos impactos ambientais. 0 resíduo industrial é o rejeito dos processos produtivos da indústria, de acordo com Kraemer (2006), ele varia de acordo com o segmento industrial e cada área possui tratamento e destinação final diferente.

A Resolução Conama $n^{\circ} 313$ (2002), relata a importância de a empresa expor o inventário de seus resíduos, descrevendo as informações de forma correta para que o Estado conheça a real situação da empresa, para que o mesmo possa controlar e gerenciar os resíduos industriais gerados no país.

\section{Classificação dos resíduos}

Existem diversas formas de classificar resíduos sólidos, a classificação quanto aos riscos potenciais de contaminação trata dos resíduos gerados em processos produtivos industriais, e poderão ser classificados quanto às suas características físico-químicas, de acordo com a Associação Brasileira de Normas Técnicas - ABNT, são diferenciados nas categorias resíduos perigosos (Classe I) e não perigosos (Classe II).

O resíduo perigoso apresenta uma ou mais das características de periculosidade citadas no artigo $3^{\circ}$ do Decreto-Lei $n^{\circ}$ 178/2006, de 5 de setembro, republicado pelo Decreto-Lei $n \times$ 73/2011, de 17 de junho. Sendo eles: explosivo, comburente, facilmente inflamável, inflamável, irritante, nocivo, 
tóxico, cancerígeno, corrosivo, infeccioso, tóxico para a reprodução, mutagênico, sensibilizante ou ecotóxico.

Dentro da categoria de resíduos não perigosos existem duas classificações, a de resíduo inerte e não inerte.

O resíduo não inerte (Classe II A) não possui tendência a sofrer uma reação química brusca, porém pode apresentar perigos ao ser humano e ao meio ambiente. Os materiais presentes nesta categoria podem possuir propriedades biodegradáveis, comburentes ou solúveis em água.

O resíduo inerte (Classe II B) é aquele que não sofre transformações físicas, químicas ou biológicas relevantes e, em consequência, não pode ser solúvel, inflamável, ou sofrer qualquer outro tipo de reação física ou química. Não apresenta características biodegradáveis, e não afeta negativamente outras substâncias com as quais entre em contato de forma suscetível a aumentar a poluição do ambiente ou prejudicar a saúde humana.

\section{Política Nacional de Resíduos Sólidos}

A política Nacional de Resíduos Sólidos foi criada através da Lei $\mathrm{n}$. 12.305 , de 5 de agosto de 2010, regulamentada pelo Decreto n. 7.404, de 23 de dezembro de 2010, passou por uma longa espera, porém é compensada pelos seus princípios, objetivos, diretrizes e instrumentos.

De acordo com Jardim, Yoshida e Machado Filho (2012), Wirth e Oliveira (2014), Stumpf, Theis e Schreiber (2018), a lei que institui a Política Nacional de Resíduos Sólidos - PNRS passou a conceber o trabalho em conjunto entre setor público, econômico-empresarial e a reconhecer 0 trabalho de cooperativas e associações de catadores, definindo que eles sejam prioridade na contratação para a execução de serviços de limpeza urbana .

Segundo o Ministério do Meio Ambiente (2012), um dos principais objetivos estabelecidos pela lei 12.305 trata da ordem de prioridade para gestão dos resíduos, iniciando pela não geração, passando pela redução, reutilização, reciclagem, tratamento dos resíduos sólidos e pôr fim à disposição final ambientalmente adequada dos rejeitos, a lei ainda aponta que de voluntária a gestão de resíduos passa a ser obrigatória.

\section{Gerenciamento de resíduos sólidos}

Conforme relatam International Solid Waste Association - ISWA e Associação Brasileira de Empresas de Limpeza Pública e Resíduos Especiais ABRELPE (2013), a gestão de resíduos é uma ferramenta que inclui aspectos que vão desde a elaboração de políticas e do desenvolvimento institucional ao projeto técnico de soluções integradas para o manejo e destinação dos resíduos sólidos. 
De acordo com Madeira (2010), a gestão dos resíduos deve estar alicerçada em condições ambientais adequadas, e considerar todos os aspectos envolvidos, desde a fonte geradora até a disposição final segura. Hodge, Ochsendorf \& Fernández (2010), relatam que a busca pela minimização do descarte e a redução de consumo de recursos naturais, têm feito as organizações buscarem pela reintegração dos resíduos nos processos produtivos, permitindo o desenvolvimento sustentável e a redução de danos ambientais.

Bautista-Lazo e Short (2013), citam a eliminação dos resíduos como um dos pilares da competitividade empresarial, e o aumento da consciência ambiental pelos consumidores tornou o tema ainda mais decisivo. Em breve a redução de resíduos deve ser como uma iniciativa vista pelas organizações independente de incentivos e regulamentações governamentais.

\section{Metodologia}

Este estudo enquadra-se em uma abordagem qualitativa pois seus objetivos buscam analisar dados para responder perguntas por meios estatísticos, e para estes fins a pesquisa realizou tratamentos de dados buscando definir padrões. O método descritivo foi utilizado devido ao registro e diagnóstico das características relacionadas aos processos, após a coleta de dados houve a análise das relações entre as variáveis sem a utilização de geração de hipóteses por dedução lógica. Os meios de investigação caracterizam o estudo em pesquisa bibliográfica e estudo de campo.

Para determinação da população do presente estudo, utilizou-se uma lista de prospecção de clientes de uma empresa prestadora de serviços tecnológicos voltada para o gerenciamento de resíduos industriais, localizada no Sul de Santa Catarina. A partir desta lista obteve-se um total geral de 42.970 empresas presentes no estado, dentre elas empresas ligadas ao setor industrial, comercial e de serviços, englobando diversos ramos de atividades.

Partindo do objetivo geral deste trabalho, percebeu-se que seria viável estudar apenas as indústrias de ramos de atividade cujo processo de transformação fosse responsável pela geração de resíduos sólidos. Desta forma foram removidas todas empresas que não possuíam os requisitos para este estudo, restando 2.105 indústrias. O tipo de amostragem utilizada foi por julgamento, esta é uma forma de amostra por conveniência em que os elementos são escolhidos porque o pesquisador acredita que estes representam a população de interesse.

O estudo foi construído a partir de fontes primárias, utilizando um questionário, dividido em blocos com dez perguntas abertas e fechadas, visando abordar assuntos relacionados ao perfil das Indústrias, resíduos industriais, práticas utilizadas e a percepção dos entrevistados. 
Assim, o contato com as empresas selecionadas ocorreu a partir da aplicação do instrumento de coleta de dados, com o envio do questionário via e-mail pela ferramenta de produção de formulários online Google Docs, realizada no período de 19 de março de 2019 a 10 de abril de 2019, obtendose 107 retornos. Os dados foram avaliados por meio da análise de frequência simples, que corresponde ao número de observações que se encontram presentes em uma classe ou intervalo específico, a partir da elaboração de gráficos utilizando a ferramenta Excel.

\section{Análise dos dados da pesquisa}

Inicialmente a pesquisa buscou descobrir em quais cidades as empresas respondentes estavam alocadas, devido ao número de respostas e a diversificação das mesmas, buscou-se agrupá-las por região.

Ao caracterizar os ramos de atividades em cada região, foi possível evidenciar o panorama industrial de Santa Catarina, com o maior volume de respostas nos ramos em que as regiões possuem destaque, citando indústrias plástica, cerâmica e metalúrgica no Sul. A região de grande Florianópolis, reconhecida por sua grande importância na área de tecnologia, aparece nesta pesquisa apenas com uma contribuição no setor de higiene pessoal. A indústria madeireira representa a região Serrana, os setores alimentício e moveleiro possuem grande volume na região Oeste. Acompanhando o cenário industrial local, o Norte ficou representado pelos setores têxtil e plástico. A indústria têxtil é responsável pelo maior número de respostas e está concentrada principalmente no Vale do Itajaí.

A caracterização aponta principalmente os resíduos de produção, também caracterizados como sobras, conceituadas por Maciel (2014), como o resíduo de materiais de operações fabris que tem valor mensurável, mas de importância relativamente pequena. Diversos setores apontaram o resíduo de produção e aparas, estes podem apresentar problemas provenientes do processo produtivo, como a falta de otimização de matéria prima. Já o setor cerâmico, teve como principal resíduo a quebra, enquadrada pela indústria como desperdício, já que não possui recuperação mensurável e ainda obriga a empresa a custos adicionais na destinação.

Com relação a classificação dos resíduos de acordo com o ramo de atividade o Gráfico 1 aponta a indústria química como a maior geradora de resíduos perigosos, de acordo com a PNRS (2010), os resíduos perigosos são aqueles que apresentam periculosidade e características como inflamabilidade, corrosividade, reatividade, toxicidade e patogenicidade. A indústria metalúrgica classifica maioritariamente seus resíduos como inertes, porém algumas os citam como perigosos, levando em consideração os resíduos gerados, tal feito pode ocorrer devido a contaminações durante o processo de transformação do produto, o mesmo se encaixa nas indústrias de artigos de decoração e automobilística. 


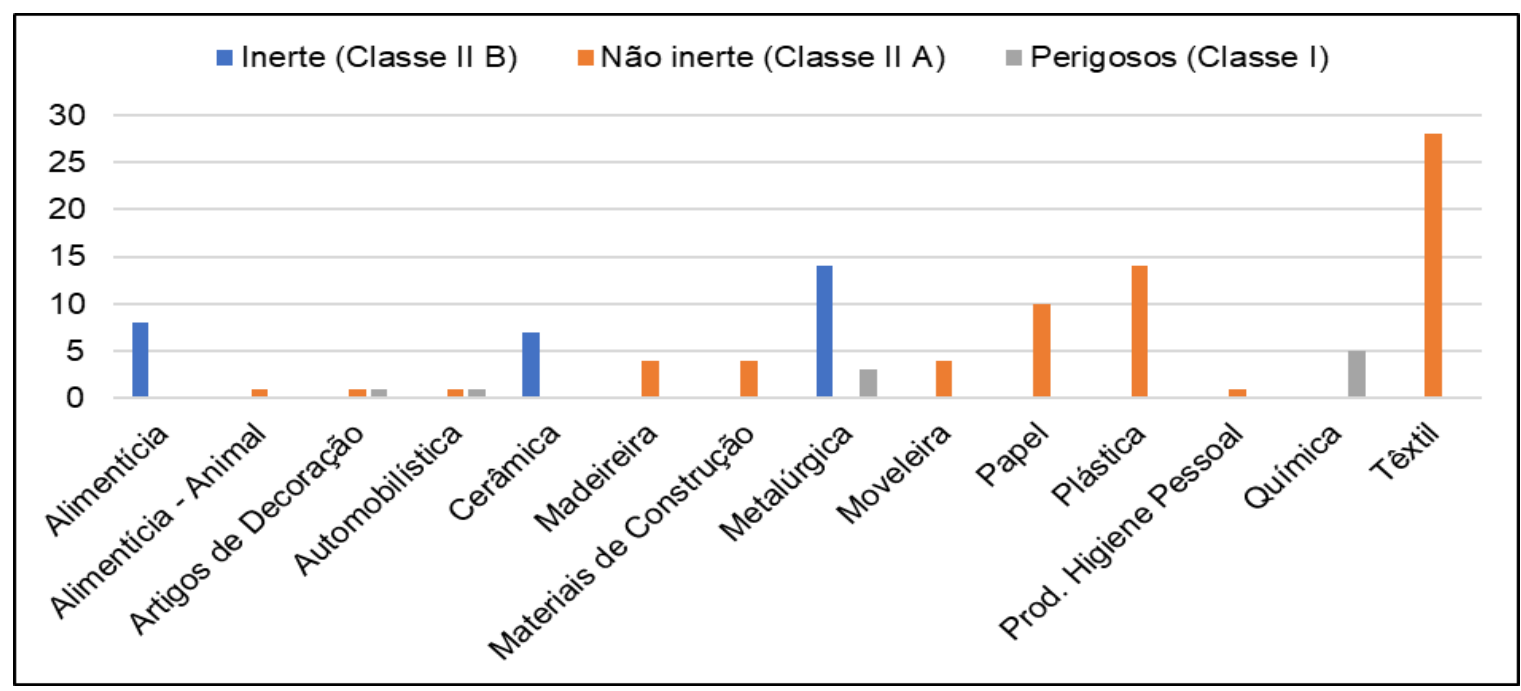

Gráfico 1: Classificação por ramo de atividade.

Fonte: Elaboração própria de acordo com dados da pesquisa. (2019)

Os resíduos inertes não têm nenhuma das características dos resíduos de classe I, com isso, não apresentam solubilidade ou combustibilidade, caso dos resíduos provenientes do setor cerâmico e alimentício. Já os resíduos não inertes podem ter propriedades como biodegradabilidade, combustibilidade ou solubilidade em água. A combustibilidade caracteriza principalmente os resíduos da indústria têxtil e de papel.

Em relação aos aspectos dos resíduos gerados, os Gráficos 2 e 3 (próxima página) relacionam os resíduos com os custos e problemas associados ao gerenciamento. Conforme Callado (2008), quando se fala em meio ambiente, o empresário imediatamente pensa em custo adicional. Dessa maneira passam despercebidas as oportunidades de uma redução dos custos. Sendo o meio ambiente um potencial de recursos ociosos ou mal aproveitados, sua inclusão no horizonte de negócios pode resultar em atividades que proporcionem lucro ou pelo menos se paguem com a energia poupada, ou outros recursos naturais.

Os custos foram classificados utilizando o número "Um" para considerar o valor baixo e "Cinco" como elevado. Observando, é possível descobrir que a percepção deste custo é relativa para a empresa e não possui grande relação com o resíduo, afinal, os mesmos em alguns casos, são enquadrados nos cinco parâmetros.

O mesmo se dá aos problemas com o gerenciamento, pelo volume de respostas a maioria das empresas entrevistadas afirma não possuírem problemas, e o paralelo com os resíduos não fica visível. 


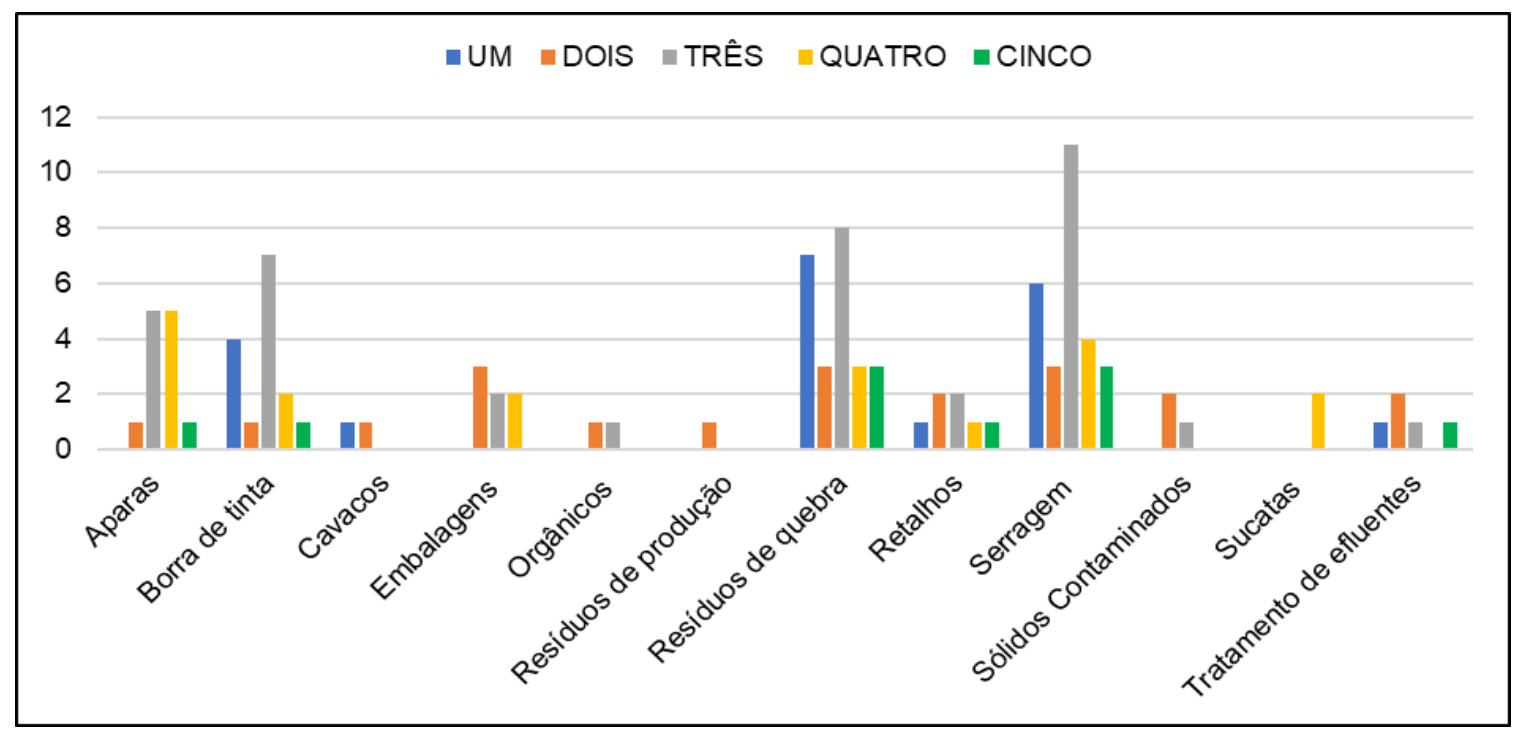

Gráfico 2: Custos relacionados aos resíduos

Fonte: Elaboração própria de acordo com dados da pesquisa. (2019)

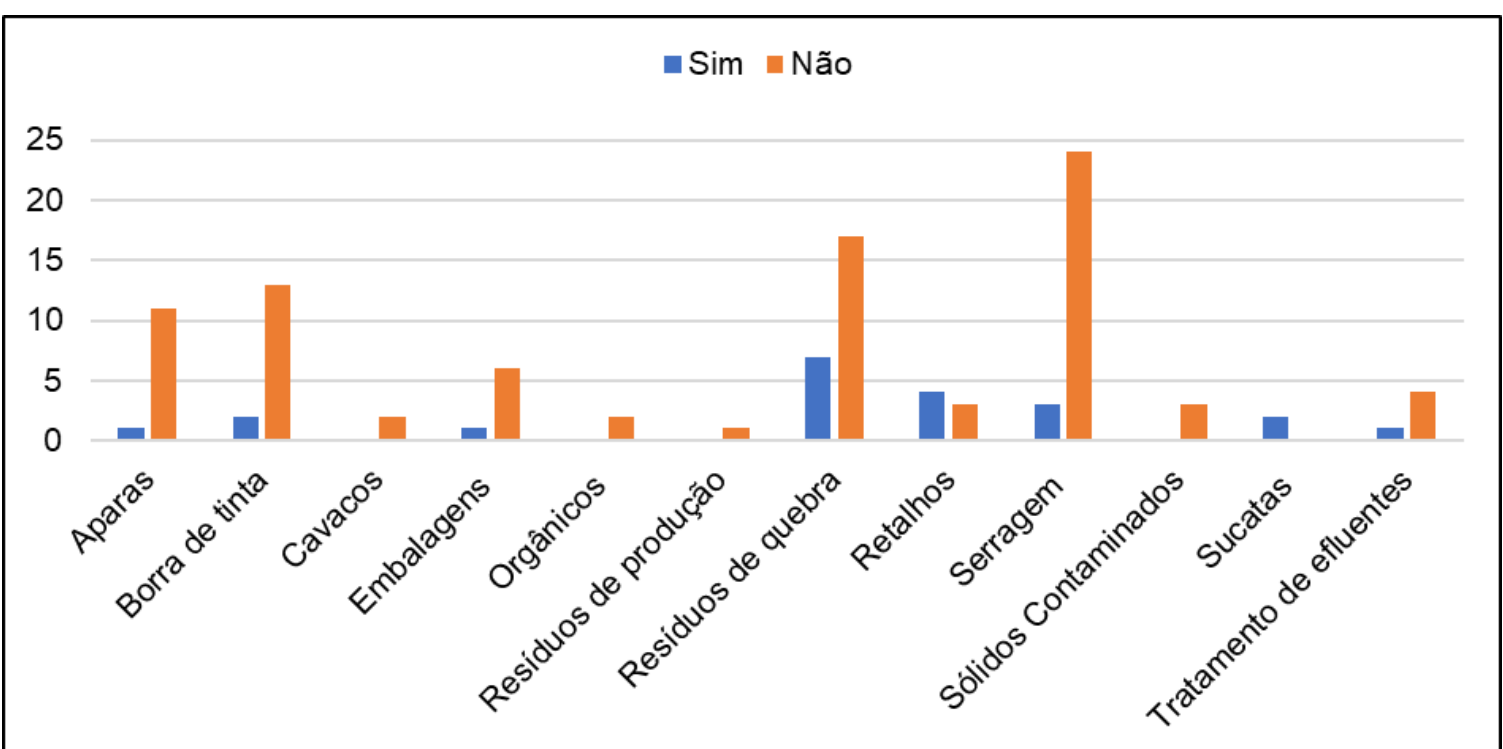

Gráfico 3: Problemas relacionados aos resíduos.

Fonte: Elaboração própria de acordo com dados da pesquisa. (2019)

Relacionando os mesmos critérios com a classificação dos resíduos, como descrevem os Gráficos 4 e 5 (próxima página), nota-se a mesma disparidade nas respostas, mesmo os resíduos perigosos não apresentam altos custos de gerenciamento, e há grande volume de respostas considerando os custos dos resíduos não inertes como baixos.

Porém é possível observar um maior volume de problemas relacionados 


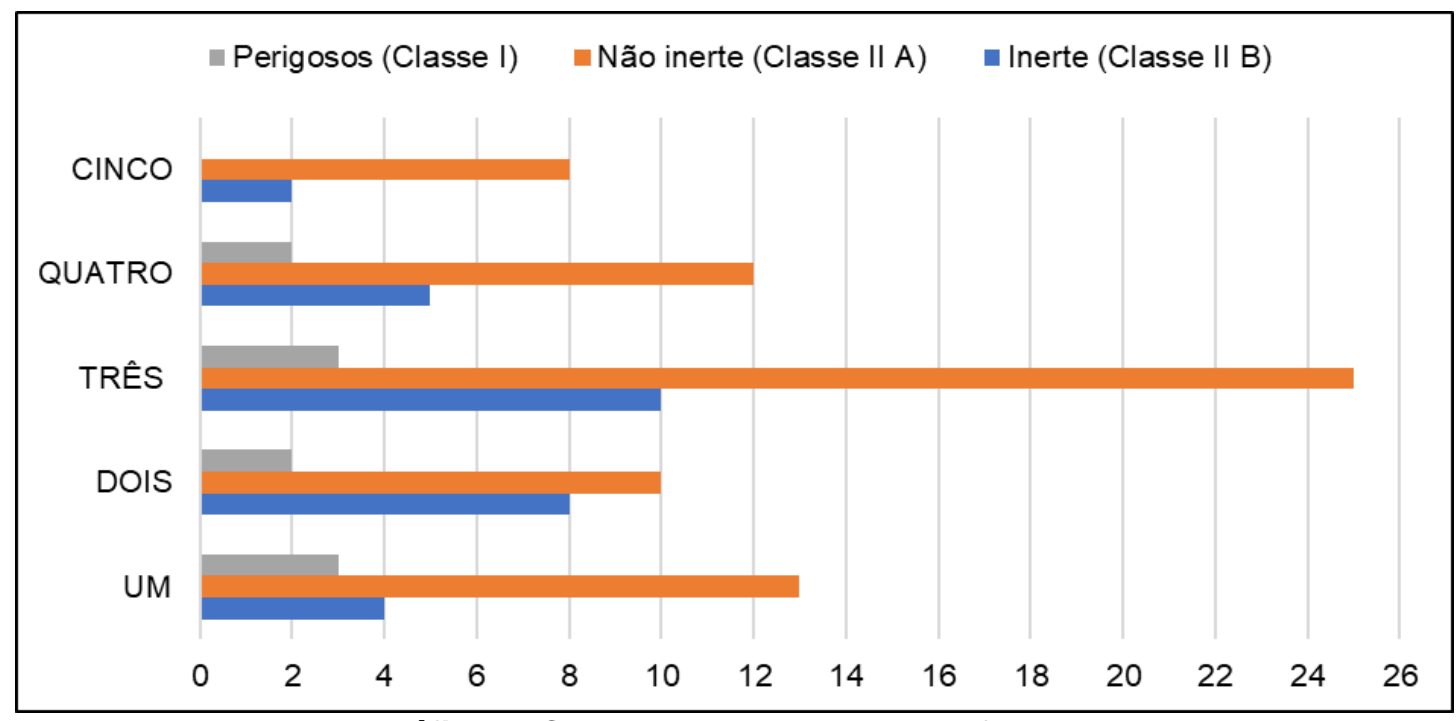

Gráfico 4: Custos relacionados a classificação.

Fonte: Elaboração própria de acordo com dados da pesquisa. (2019)

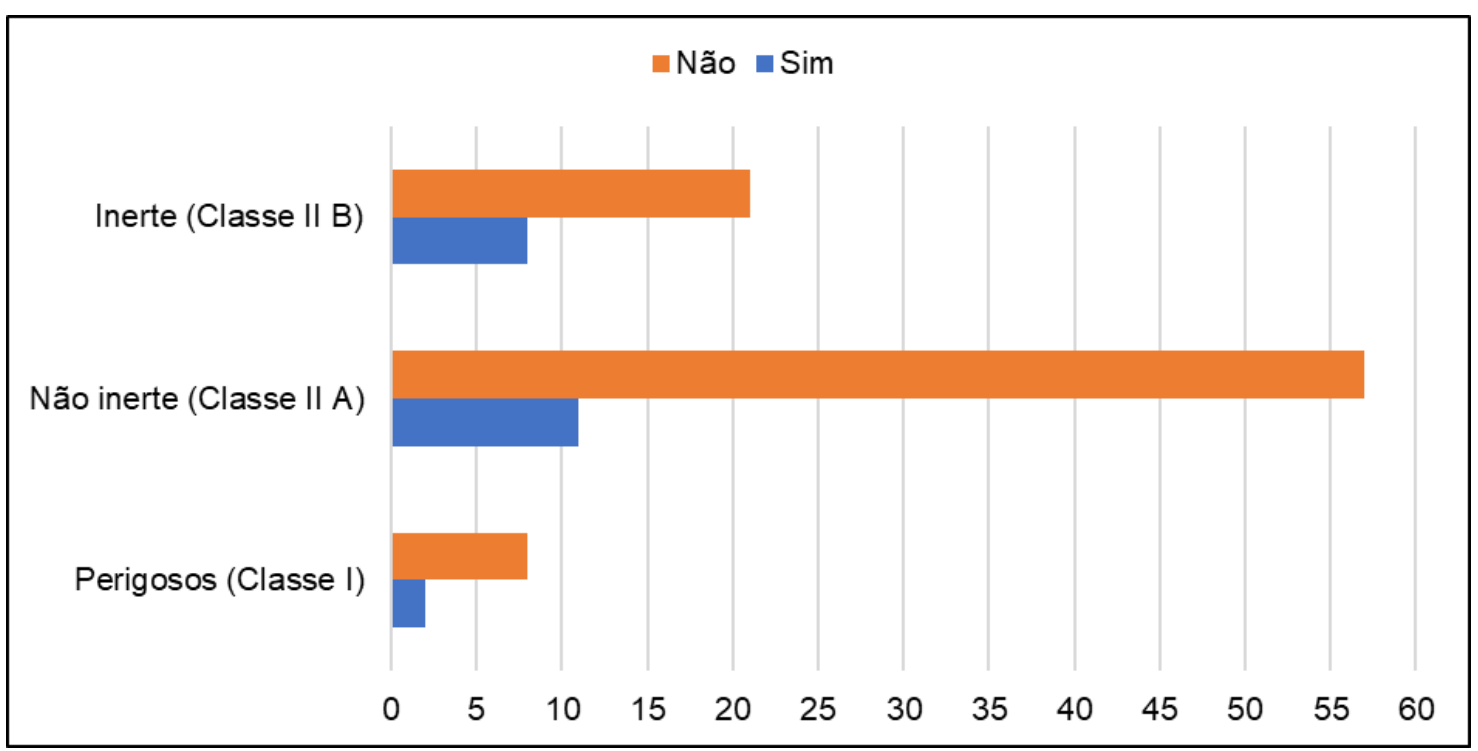

Gráfico 5: Problemas relacionados a classificação.

Fonte: Elaboração própria de acordo com dados da pesquisa. (2019)

Observando a destinação empregada pelas empresas, conforme o Gráfico 6, é possível notar que quase todos os resíduos possuem parte de sua destinação em aterros sanitário e industriais, de acordo com a NBR 8419 (ABNT, 1992), o aterro sanitário utiliza princípios de engenharia para manter os resíduos sólidos à menor área possível e reduzi-los ao menor volume possível, após são cobertos com uma camada de terra. 


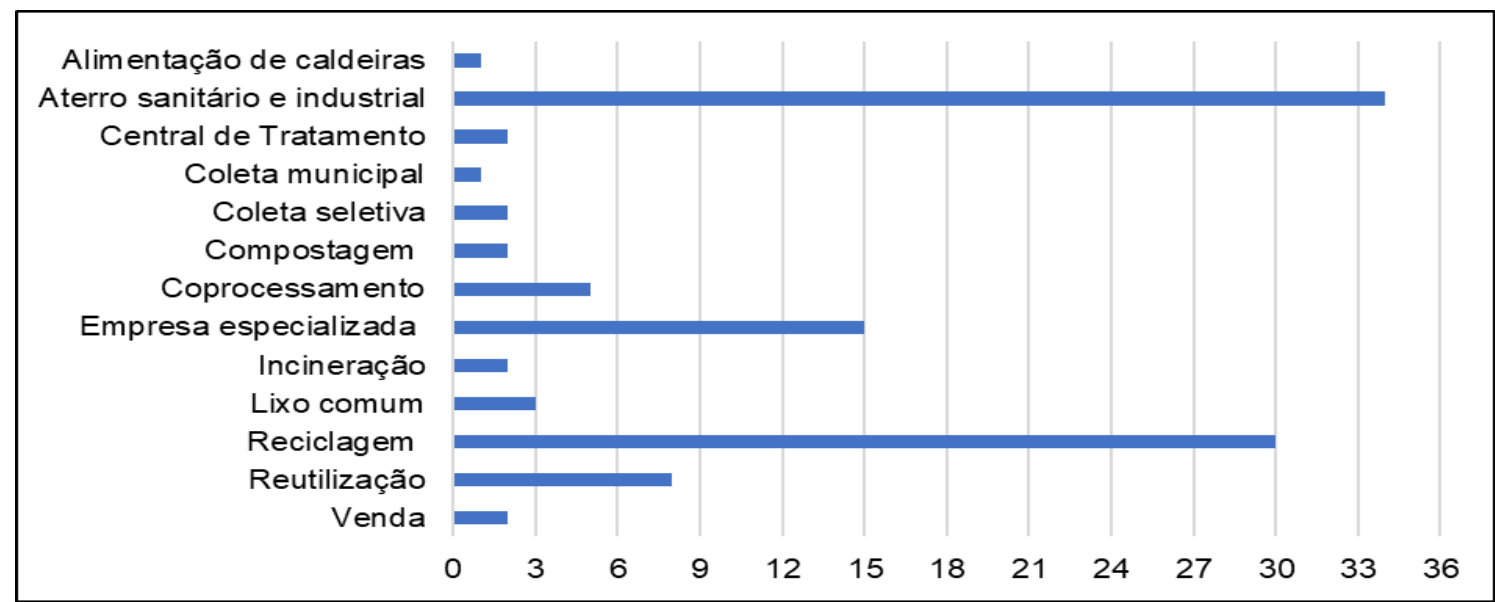

Gráfico 6: Destinação.

Fonte: Elaboração própria de acordo com dados da pesquisa. (2019)

$\mathrm{Na}$ mesma norma consta que nos aterros industriais são armazenados os resíduos sólidos produzidos pelas indústrias dos mais variados segmentos. Esses tipos de aterro precisam contar com impermeabilização das trincheiras, tratamento de afluentes e dos gases liberados pelos materiais descartados, sistema de drenagem das águas pluviais e barracões especiais de reciclagem, armazenagem e manutenção. Os aterros industriais são classificados nas classes I, II ou III, conforme a periculosidade dos resíduos a serem dispostos.

A reciclagem, componente importante no gerenciamento de resíduos, também é bastante empregada, principalmente para as aparas e retalhos, Silva (1975), cita que a reciclagem é transformar ou dar uma nova utilidade para materiais ou produtos já utilizados. O lixo comum, apesar de pouco, também foi citado tal fato pode significar que a empresa não sabe ou desconhece uma forma correta e ambientalmente adequada para o descarte.

Segundo Pôrto, (2017), as empresas costumam definir o custo de um resíduo considerando apenas o custo de sua destinação. Porém de acordo como princípio da conservação da massa esse resíduo é formado por matériasprimas que não foram transformadas em produto final. Portanto, o custo real do resíduo é o custo da destinação final mais o custo das matérias-primas que formaram o resíduo.

O Gráfico 7 relaciona os custos com a forma de destinação, o parâmetro "Três" foi o mais citado dentre as destinações, informando que o custo de gerenciamento não apresenta grande gasto financeiro para a empresa. Nos parâmetros "Quatro" e "Cinco" as destinações mais citadas tratam dos aterros sanitários, coprocessamento e a reciclagem. 


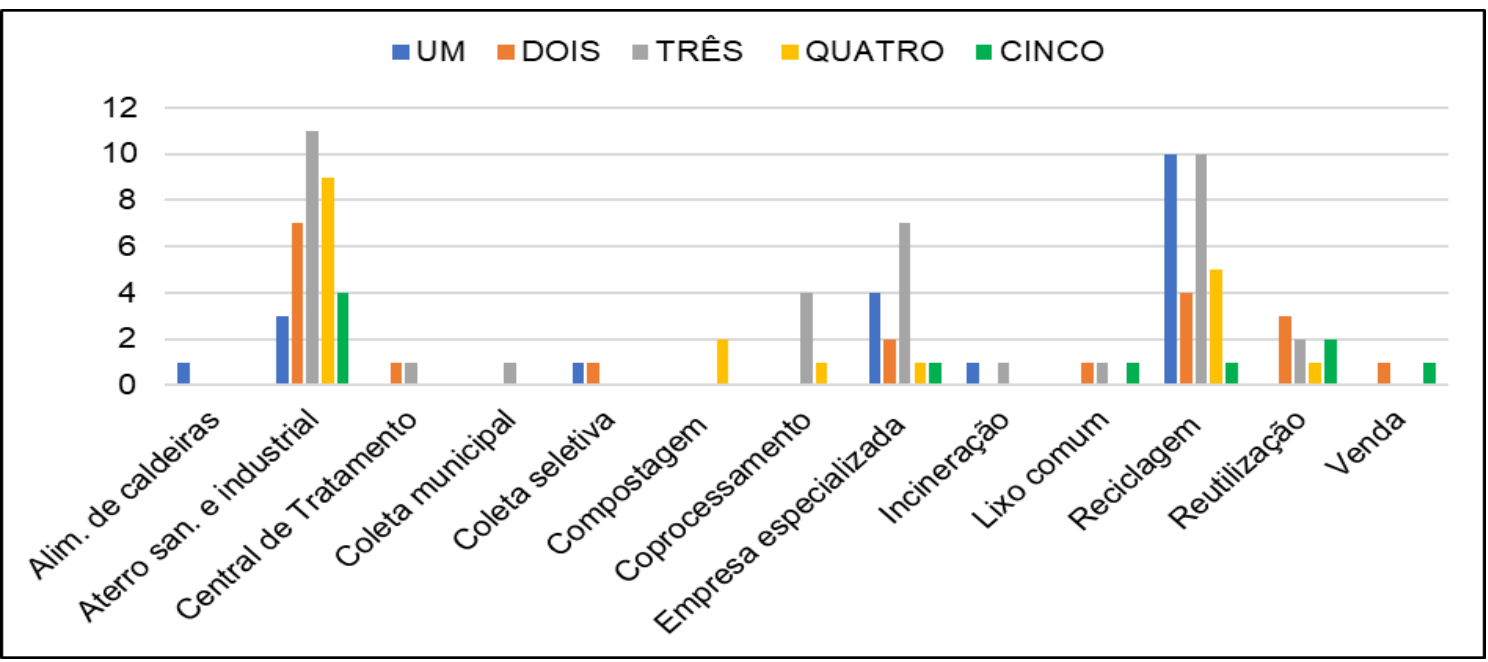

Gráfico 7: Custos e Destinação.

Fonte: Elaboração própria de acordo com dados da pesquisa. (2019)

De acordo com Vanti (1999), filosofias organizacionais na busca por um ambiente de qualidade são uma preocupação cada vez mais frequente dos administradores para atingir os objetivos das organizações que presidem de forma eficiente. Gerenciar resíduos significa adotar de forma efetiva e sistemática, um conjunto de ações nas etapas de coleta, transporte, transbordo, tratamento, destinação final e disposição final ambientalmente adequada.

Desta maneira as empresas foram questionadas a respeito da utilização de alguma ferramenta para o gerenciamento dos resíduos gerados. Conforme resultados apresentados no Gráfico 8 (próxima página), nota-se que a maioria das empresas entrevistadas fazem uso de algum tipo de ferramenta. Ao relaciona-la com os custos observa-se que sua utilização pode ser um fator que interfere no custo de gerenciamento, pois grande parte das empresas que fazem utilização de uma aplicaram os parâmetros "Três" e "Quatro" para classificar seus custos, já no emprego do parâmetro "Cinco" a ferramenta não foi um fator que apresentou interferência.

Com o objetivo de avaliar a percepção da empresa sobre o gerenciamento de resíduos, fora questionado a respeito das vantagens do gerenciamento e problemas enfrentados pelas empresas entrevistadas.

Com relação as vantagens competitivas que o correto gerenciamento pode gerar, o Gráfico 9 (próxima página) apresenta que mais da metade das empresas acreditam que sim. Um dos fatores que pode ser considerado como vantagem competitiva é a aquisição de rótulos ambientais, para o Conselho Nacional de Defesa Ambiental - CNDA (2015), um rótulo é considerado a certificação de produtos adequados ao uso que apresentam menor impacto ao meio ambiente em relação a outros produtos comparáveis disponíveis no mercado e tem como objetivo promover a melhoria da Qualidade Ambiental de 
produtos e processos mediante a mobilização das forças de mercado pela conscientização de consumidores e produtores.

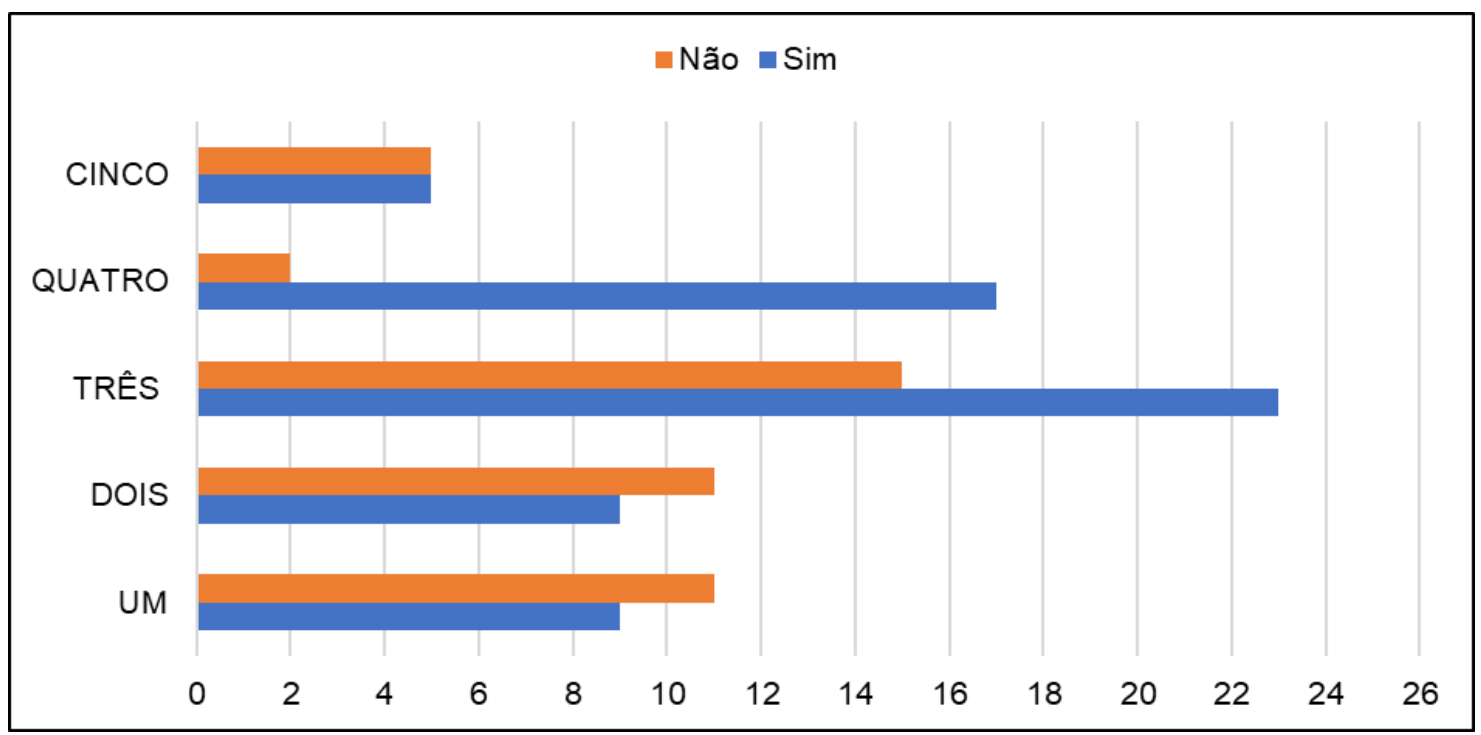

Gráfico 8: Custos e Ferramenta.

Fonte: Elaboração própria de acordo com dados da pesquisa. (2019)

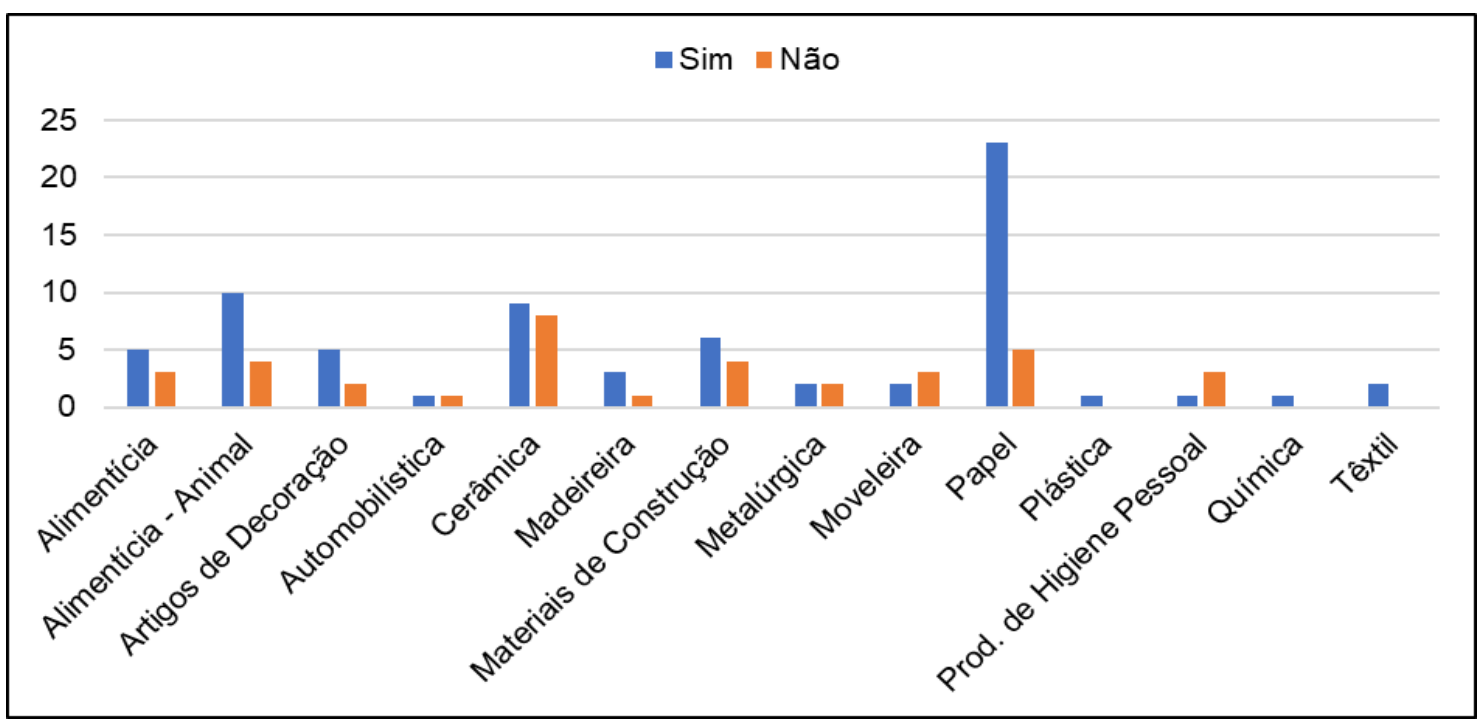

Gráfico 9: Vantagem competitiva por ramo de atuação

Fonte: Elaboração própria de acordo com dados da pesquisa. (2019)

Para Voltolini (2010), o brasileiro ainda não valoriza tanto o selo verde quanto o de países como os EUA, Canadá, Alemanha e Japão. Por causa da falta desse interesse local, várias instituições atuam principalmente certificando produtos brasileiros para exportação. 
É possível observar que grande parte das respostas positivas são provenientes da indústria têxtil, esta constitui um dos setores que contribui para a formação da pauta exportadora catarinense, considerada a oitava maior do País.

Dentre as vantagens competitivas citadas pelas empresas, a percepção que o gerenciamento gera fica voltado principalmente a respeito da redução dos desperdícios e consequentemente dos custos com resíduos, outros pontos citados foram a respeito da correta destinação que evita passivos ambientais, oportunidades de reaproveitamento dos materiais e benefícios sociais.

Com relação aos problemas enfrentados com o gerenciamento de resíduos, grande parte das empresas entrevistadas afirma que não os possuem, como é possível observar no Gráfico 10. Dentre as que possuem, a indústria cerâmica possui mais da metade de suas respostas, o seu maior problema citado é relativo ao treinamento dos funcionários no momento da separação dos resíduos, porém ao analisar de forma mais abrangente outra causa pode ser a caracterização do seu principal resíduo, que possui grande dificuldade de gerar um descarte lucrativo e poucas maneiras para seu reaproveitamento já que sua reciclagem não é possível.

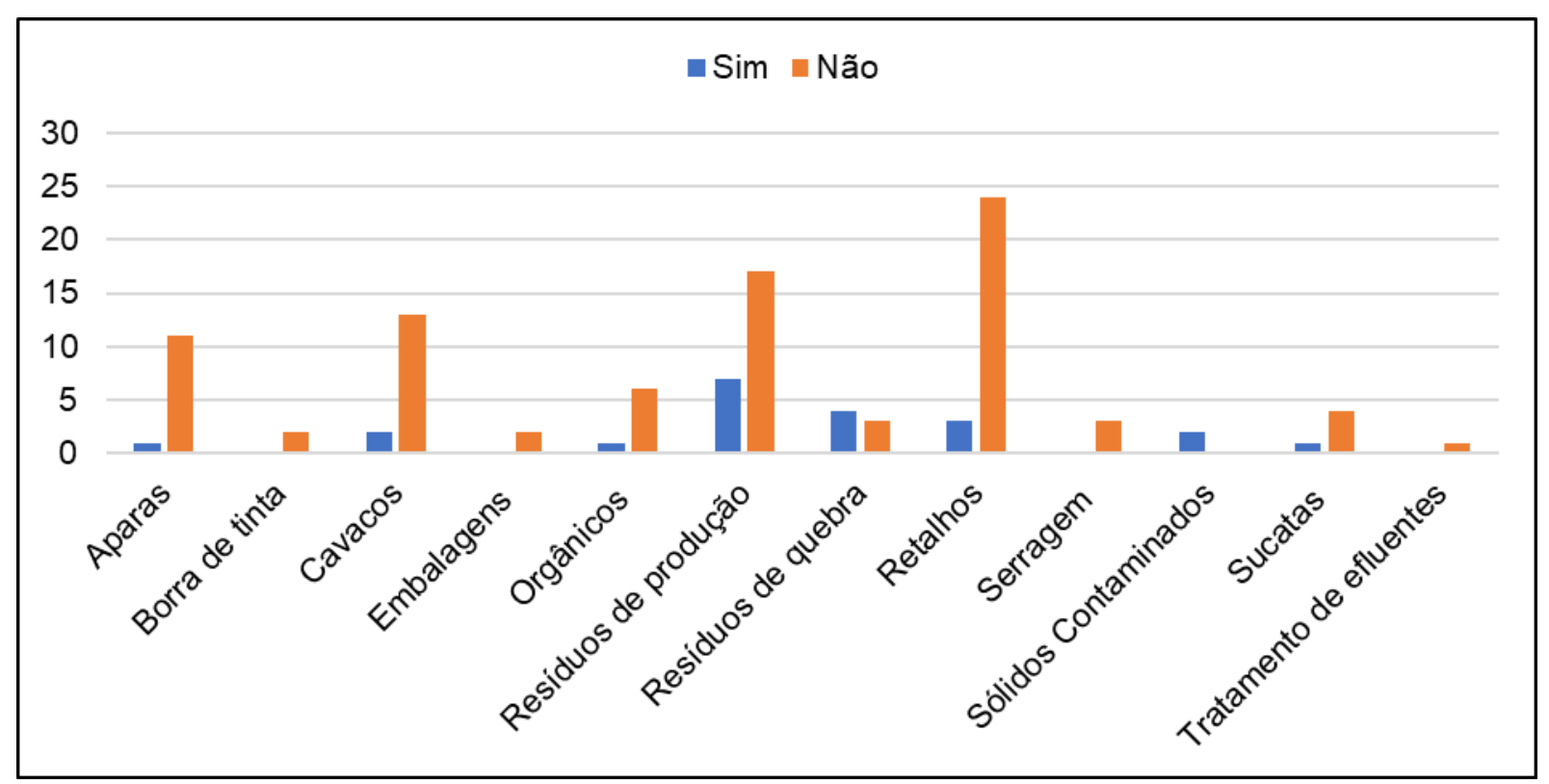

Gráfico 10: Problemas por Resíduos.

Fonte: Elaboração própria de acordo com dados da pesquisa. (2019)

Dentre os principais problemas, o treinamento e colaboração dos funcionários para separação correta dos resíduos foi um aspecto citado principalmente pelas indústrias cerâmica e metalúrgica, tal fato aponta que independente dos métodos e ferramentas utilizados, a colaboração humana é um fator fundamental para o bom andamento dos projetos desenvolvidos. $O$ reaproveitamento dos materiais são questões apontadas pelas mesmas 
indústrias já que os resíduos gerados possuem difícil destinação. Os meios de destinação final e a falta de empresas especializadas no descarte dos materiais são apontados como problemas pelas indústrias de materiais de construção e plástica. Empresas pertencentes a indústria têxtil citam as mesmas dificuldades para alcançar os padrões desejados voltados ao gerenciamento de seus resíduos.

\section{Conclusão}

Valle (1995), acredita que as políticas ambientais não devem ser encaradas apenas como uma obrigação para as empresas, e sim como um instrumento para garantir uma boa imagem perante seu público, apresentando a preocupação voltada ao meio em que vive.

Tocchetto (2005), descreve que a globalização das questões relacionadas ao meio ambiente através da busca da sustentabilidade promoveu a necessidade de harmonizar o desenvolvimento econômico e a preservação ambiental, conseguido através da aplicação dos conceitos de gestão a continuidade e o desenvolvimento.

Desta forma, este estudo objetivou identificar as percepções e ações desenvolvidas pelas indústrias Catarinenses relacionadas ao gerenciamento dos resíduos sólidos industriais. Os resultados apresentaram que as empresas pesquisadas estão vinculadas aos mais variados setores que contemplam a economia Catarinense, gerando os mais variados tipos de resíduos, em grande maioria resíduos de produção, aparas e retalhos, ocasionados em muitas situações pela má otimização das matérias primas no processo produtivo.

Observa-se que algumas alternativas de monitoramento vêm sendo utilizadas pelas empresas para melhor controle e gerenciamento de seus resíduos, porém há carência no comprometimento dos colaboradores e meios mais interessantes para destinação final. No que diz respeito ao correto gerenciamento, grande parte das empresas percebem os benefícios gerados além da obrigação legal.

Dada à importância deste assunto, como proposta, sugere-se a implementação contínua e consistente de uma da cultura empresarial preocupada com os danos gerados ao ambiente ao qual está inserido. Sendo assim, estudos futuros podem aprofundar o tema em questão buscando entender 0 impacto que a preocupação ambiental representa para 0 consumidor final e se tal questão é um fator decisivo para a compra. Também mapear de forma profunda os custos reais que o gerenciamento gera, visto que tal ponto foi uma limitação no estudo atual. 


\section{Referências}

ASSOCIAÇÃO BRASILEIRA DE NORMAS TÉCNICAS (ABNT). Apresentação de projetos de aterros sanitários de resíduos sólidos urbanos. NBR 8419. São Paulo, 1992.

ASSOCIAÇÃO BRASILEIRA DE NORMAS TÉCNICAS (ABNT). NRB 10004: Resíduos sólidos - Classificação. Rio de Janeiro. 71 p. Disponível em: $<$ http://www.suape.pe.gov.br/images/publicacoes/normas/ABNT NBR n 10004 2004.pdf> Acesso em: 10 out. 2018.

AYRES, R.U. Sustainability economics: Where do we stand? Ecological Economics, v.67, n.2. 2018.

BARBOSA, P.R.A. Índice de sustentabilidade empresarial da bolsa de valores de São Paulo (ISE-BOVESPA): Exame da adequação como referência para aperfeiçoamento da gestão sustentável das empresas e para formação de carteiras de investimento orientadas por princípios de sustentabilidade corporativa. Disponível em: <http://www.coppead.ufrj.br/ upload/publicacoes/Paulo Barbosa.pdf> Acesso em: 30 out. 2018.

BARTELMUS, P. Dematerialization and capital maintenance: two sides of the sustainability coin. Ecological Economics, v.46, n.1., 2018.

BAUTISTA-LAZO, S.; Short, T. Introducing the all seeing eye of business: a model for understanding the nature, impact and potential uses of waste. Journal of Cleaner Production, 40, 141-150.

BOFF, L. Sustentabilidade: O que é - o que não é. 2017. Petrópolis, RJ: Editora Vozes.

BRASIL. Lei № 12.305, de 2 de agosto de 2010. Política Nacional de Resíduos Sólidos; altera a Lei no 9.605, de 12 de fevereiro de 1998; e dá outras providências. Disponível em: <http://www2.mma.gov.br/port/conama llegiabre.cfm?codlegi=636> Acesso em: 04 out. 2018.

CALLADO, A.L.C. Importância da Gestão dos Custos Ambientais. Sustentabilidade e Gestão Ambiental.

CINQUETTI, H.S. Lixo, resíduos sólidos e reciclagem: uma análise comparativa de recursos didáticos. Educar, Curitiba, n. 23, p. 307-333. Editora UFPR. Disponível em: <http://www.scielo.br/pdf/er/n23/n23a18.pdf> Acesso em: 04 out. 2018.

CONSELHO NACIONAL DE DEFESA AMBIENTAL (CNDA). Disponível em: $<$ http://www.cnda.org.br> Acesso em: 20 abr. 2019.

DEMAJOROVIC, J. Da política tradicional de tratamento do lixo à política de gestão de resíduos sólidos: as novas prioridades. Revista de Administração de Empresas. São Paulo, v.35, n.3, p.88-93, maio/jun.

ETHOS - Instituto Ethos de Empresas e Responsabilidade Social. Disponível em: <www.ethos.org.br>. Acesso em: 16 Mar.2019 
HODGE, M.; OCHSENDORF, J.; FERNÁNDEZ, J. Quantifying potential profit from materia: recycling a case study in brick manufacturing. Journal of Cleaner Production, 18 (12), 1190- 1199.

ISWA. International Solid Waste Association; ABRELPE. Associação Brasileira de Empresas de Limpeza Pública e Resíduos Especiais .Resíduos sólidos: manual de boas práticas no planejamento. Disponível em: $<$ http://arquivo.ambiente.sp.gov.br/cpla/2013/03/Manual-Boas-Praticas.pdf> Acesso em: 02 nov. 2018.

JARDIM, A.; YOSHIDA, C.Y.M.; MACHADO FILHO, J.V.Política nacional, gestão e gerenciamento de resíduos sólidos. 1. ed. Barueri, SP: Manole. $732 \mathrm{p}$.

KEIM, E.J. Abordagem das relações entre os componentes ambientais nos livros didáticos de $1^{\circ}$ grau. Rio de Janeiro, UFRJ.

KRAEMER, M.E.P. Resíduos industriais e a questão ambiental associada à contabilidade aplicada ao ambiente natural. Pensar Contábil. v.7, n.30, p.1-14.

LAYRARGUES, P.P. O desafio empresarial para a sustentabilidade e as oportunidades da Educação Ambiental. Cidadania e meio ambiente. Salvador: CRA. v. 1, p. 96-110. Disponível em: <http://professor.pucgoias. edu.br/SiteDocente/admin/arquivosUpload/17973/material/EMPRESAS\%20CO M\%20RESPONSABILIDADE\%20AMBIENTAL.pdf> Acesso em: 08 ago. 2018.

LÉLÉ, S. M. Sustainable Development: A Critical Review. World Development. Vol. 19, oㅜ 6: p. 607-621, 1991.

LIMA, M.J.A. Ecologia humana. Petrópolis, Vozes.

MACIEL. E. Custo da qualidade e seus benefícios. Disponível em: $<$ https://repositorio.pgsskroton.com.br/bitstream/123456789/616/1/artigo\%2024 >.pdf Acesso em: 19 abr. 2019

MADEIRA, R. F. O setor de saneamento básico no Brasil e as implicações do novo marco regulatório para a universalização do acesso. Revista BNDES, 33, $123-154$.

MARQUES, J.R. Meio Ambiente Urbano. Rio de Janeiro: Forense Universitária.

MINISTÉRIO DO MEIO AMBIENTE. Planos de gestão de resíduos sólidos: manual de orientação Brasília. Disponível em: <http://www.mma.gov.br/ estruturas/182/ arquivos/manual de residuos solidos3003 182.pdf> Acesso em: 10 out. 2018.

OLIVEIRA, J.A. Responsabilidade social em pequenas e médias empresas. Disponível em: <http://bibliotecadigital.fgv.br/ojs/index.php/rae/article/view/ 39220/37956> Acesso em: 16 mar. 2019. 
PÔRTO, L.C. E se as empresas soubessem o custo real de seus resíduos? Disponível em: <https://cenedcursos.com.br/meio-ambiente/empresas-custoreal-residuos >. Acesso em 19 abr. 2019.

Resolução $n^{0}$ 313, de 29 de outubro de 2002. Dispõe sobre o Inventário Nacional de Resíduos Sólidos Industriais. Brasília: Diário Oficial da União, 22 de novembro de 2002. Disponível em: <http://www2.mma.gov.br/ port/conama/legiabre.cfm?codlegi=335> Acesso em: 02 nov. 2018.

RIBEIRO, M.S. Contabilidade ambiental. São Paulo: Saraiva, $2^{2}$ Ed.

ROMEIRO, A.R. Desenvolvimento sustentável: uma perspectiva economicoecológica. Disponível em: <http://www.scielo.br/pdf/ea/v26n74/a06 v26n74.pdf> Acesso em: 02 nov. 2018.

ROOS A.; BECKER E.L.S. Educação Ambiental e sustentabilidade. Revista Eletrônica em Gestão, Educação e Tecnologia Ambiental. V (5), n5, p. 857. 2018.

SACHS, I. From poverty trap to inclusive development in LDCs. Economic and Political Weekly, 1802-1811.

SANTAELLA, S.T., et al. Resíduos sólidos e a atual política ambiental brasileira. Fortaleza: UFC. LABOMAR. NAVE. Disponível em: $<$ http://www.repositoriobib.ufc.br/000011/00001121.pdf >. Acesso em: 02 nov. 2018.

SEBRAE. Gestão de resíduos sólidos uma oportunidade para o desenvolvimento municipal e para as micro e pequenas empresas. Disponível em: <http://www.resol.com.br/cartilhas/gestao de residuos solidossebrae.pdf>. Acesso em: 04 out. 2018.

SERTEK, P. Responsabilidade Social e Competência Interpessoal. Curitiba: lbpex.

SILVA, P.M. A poluição. São Paulo, Difel. Processamento de Polímeros. 2. ed. Florianópolis: Ed. UFSC.

STUMPF, U.D.; THEIS, V.; SCHREIBER, D. Gestão de Resíduos Sólidos em Empresas Metalomecânicas de Pequeno Porte. Revista de Gestão Ambiental e Sustentabilidade, v. 7, n. 2, p. 230-247.

TOCCHETTO, M.R.L. Gerenciamento de resíduos sólidos industriais. Disponível em: <http://www.blogdocancado.com/wp-content/uploads/2012/04/ gerenciamento-de-residuos-solidos-industriais.pdf> Acesso em: 20 abr. 2019.

VALLE, C.E. Qualidade ambiental: como ser competitivo protegendo o meio ambiente: (como se preparar para as normas ISO 14000). São Paulo: Pioneira, 1995. $117 \mathrm{p}$.

VAN BELLEN, H.M. Desenvolvimento Sustentável: uma Descrição das Principais Ferramentas de Avaliação. Ambiente \& Sociedade - V. VII, №. 1 jan./jun. 
VANTI, N. Ambiente de qualidade em uma biblioteca universitária: aplicação do $5 \mathrm{~S}$ e de um estilo participativo de administração. Disponível em: <http://www.scielo.br/pdf/ci/v28n3/v28n3a11.pdf>. Acesso em: 20 abr.2019.

VOLTOLINI, R. Rótulos, selos e certificações verdes: uma ferramenta para - consumo consciente. Disponível em: <https://www.ideiasustentavel.com.br/pdf/IS20\%20-\%20Dossie\%20v3.pdf> Acesso em: 20 abr. 2019.

WIRTH, I.G. OLIVEIRA, Cristiano Benites. A política nacional de resíduos sólidos $e$ os modelos de gestão. Disponível em: $<$ http://www.ipea.gov.br/agencia/images/stories/PDFs/livros/livros/160331 livro catadores cap 9.pdf> Acesso em: 04 out. 2018. 